\title{
EFFORTS TO DEVELOP DISASTER-RESPONSE MANAGEMENT CAPABILITIES USING THE CASE METHOD
}

\author{
Hisato NAGATA ${ }^{1}$ and Kenji KINOSHITA ${ }^{2}$ \\ ${ }^{1}$ Member of JSCE, Technical Research and Development Division, Kumagai Gumi Co., Ltd. \\ (2-1, Tsukudo-cho, Shinjuku-ku, Tokyo 162-8557, Japan) \\ E-mail: hnagata@ku.kumagaigumi.co.jp \\ ${ }^{2}$ Member of JSCE, Dept. of Civil Eng., Kumagai Gumi Co., Ltd. \\ (2-1, Tsukudo-cho, Shinjuku-ku, Tokyo 162-8557, Japan) \\ E-mail: kenji.kinoshita@ku.kumagaigumi.co.jp
}

\begin{abstract}
The case method, which has been used in other fields such as business administration, is gaining attention as an approach to developing human resources capable of crisis management in the event of a large-scale disaster. This paper reports on the development of learning materials that contain examples of actions taken by infrastructure administrators and construction firms during the Great East Japan Earthquake. This paper also considers methods of using such cases in simulation classes and describes studies using the case method in on-the-job training to develop disaster-response management capabilities. Many institutions are working on passing down lessons learned from disasters to the next generation. It is believed that providing specific approaches for human resource development will not only enhance the capability of responding to expected large-scale disasters but also secure and develop human resources, one of the key issues in the civil engineering field.
\end{abstract}

Key Words: case method, large-scale disaster, disaster-response management capability,human resource development

\section{INTRODUCTION}

It has become clear that effectively using resources (personnel, machinery, materials, etc.) held by facility managers in the construction field and the construction-related industries in various phases including the initial response and recovery efforts at an early stage of the Great East Japan Earthquake yielded significant outcomes. This was true regardless of whether such efforts were done in a collaborative or autonomous manner ${ }^{1}$.

However, in the chaos of such a greater-thanexpected disaster, many of the successful outcomes resulted from flexible responses that were made possible thanks to mutual trust between the relevant parties. They can also be attributed to the on-the-spot decision-making abilities accumulated through daily construction work, rather than actions done in line with manuals and agreements.

Responding to a large-scale disaster requires management capabilities during abnormal circumstances such as split-second decision-making and execution given limited information and resources available.

It is true that the ability to respond to disasters may largely vary depending on whether or not the relevant people exercise their management capabilities.

Figure 1 illustrates an example of the initial response taken in the construction field.

In Japan, being prepared for large-scale earthquakes is a crucial issue. In particular, earthquakes directly below a populated area like the Kumamoto Earthquakes in April 2016 can strike suddenly and it is difficult to predict them. In light of this, developing disaster-response management capabilities is considered to be extremely important, as with taking disaster prevention and mitigation measures in terms of hardware (infrastructure, etc.) and software (training, etc.). This study organizes the elements necessary to exercise disaster-response management capabilities (knowledge, experience, skills and know-how of people and organizations concerned; collaboration between relevant parties; disaster prevention and mitigation measures in terms of hard- 


\begin{tabular}{|c|}
\hline $\begin{array}{l}\text { Entities related } \\
\text { to construction }\end{array}$ \\
\hline $\begin{array}{l}\text { Infrastructure managers: } \\
\text { National and local } \\
\text { government } \\
\text { Highwaycompanies } \\
\text { Railway companies } \\
\text { Lifeline utility companies }\end{array}$ \\
\hline $\begin{array}{l}\text { Construction-related } \\
\text { industries: } \\
\text { Contractors } \\
\text { Construction consultants } \\
\text { Surveyingcompanies } \\
\text { Construction equipment } \\
\text { leasing } \\
\text { companies }\end{array}$ \\
\hline $\begin{array}{l}\text { Construction support: } \\
\text { Educational and research } \\
\text { institutions } \\
\text { Public benefit corporations } \\
\text { and NPOs }\end{array}$ \\
\hline $\begin{array}{l}\text { Construction engineers } \\
\text { Engineers in the construction } \\
\text { field }\end{array}$ \\
\hline
\end{tabular}

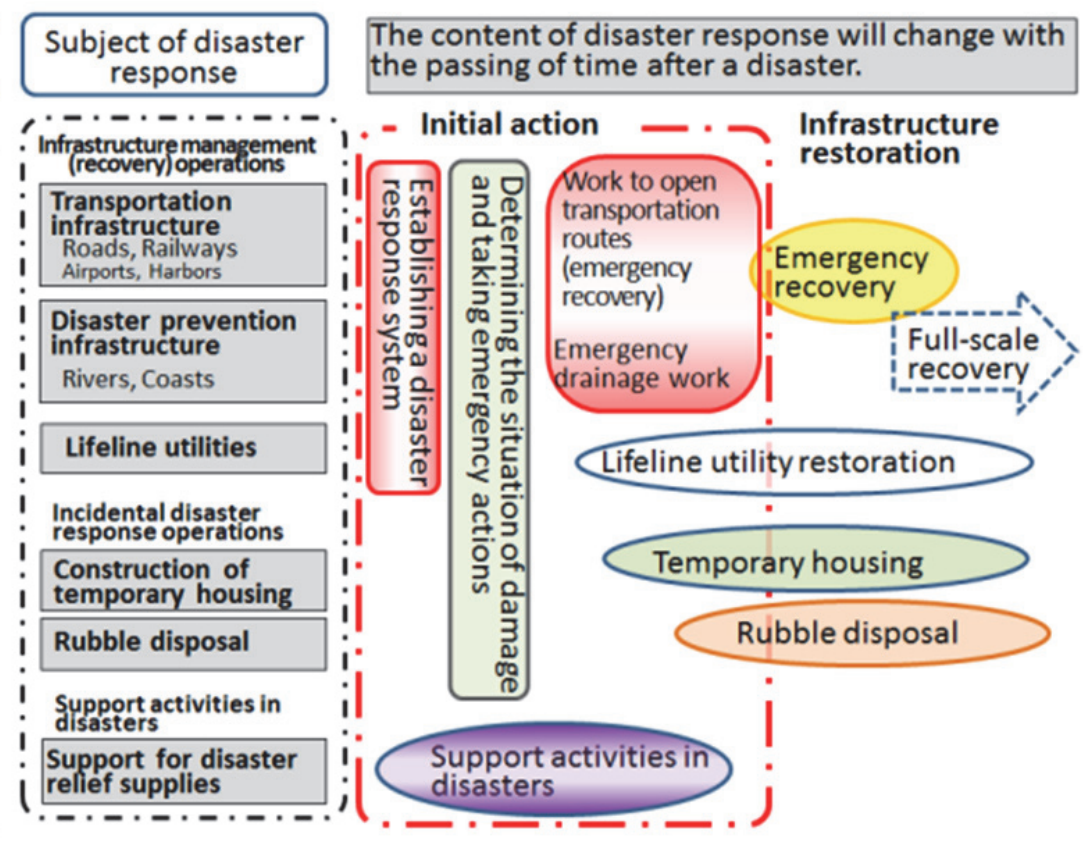

Fig. 1 Disaster-response management in the construction field (initial action) (example of the Great East Japan Earthquake).

ware and software; activities in normal situations, etc.). It also examines how the case method can be used to develop disaster-response management capabilities based on examples of responses taken in large-scale earthquakes. The study also aims to verify specific approaches to be used in human resource development through reviewing the simulation using the case method by the Construction Management Committee of Japan Society of Civil Engineers (JSCE).

\section{DISASTER-RESPONSE MANAGEMENT CAPABILITIES}

The Great East Japan Earthquake triggered powerful tsunami waves, which caused extensive and severe damage. The impact of such a giant tsunami has made clear the importance of developing and expanding software measures to cover the matters that cannot be covered by hardware measures. What Japan has seen and experienced through the tsunami disaster has made it desirable that in addition to the existing hardware-related measures focusing on the development of social infrastructure, software measures be put in place such as the establishment of a disaster prevention education system that supports active initiatives by individuals in various positions to prevent disasters.

As with implementing disaster prevention and mitigation measures, developing disaster-response management capabilities in preparation for giant disasters such as the Nankai Trough Earthquake and
Tokyo Inland Earthquake, which are highly likely to occur, is considered to be one of the important disaster relief programs.

In this study, the disaster-response management capabilities are defined as capabilities to make effective use of resources under limited conditions. These capabilities are positioned as comprehensive abilities that infrastructure facility managers, construction firms and their staff need to have in order to take the initial response appropriately in the event of a disaster. Such abilities include grasping the situation, choosing and deciding what actions should be taken, making decisions on the implementation of such actions, and organizing resources within/outside the organization to implement them.

In order to overcome disaster response-related challenges under a difficult situation immediately after the occurrence of a disaster, it is important for individuals to play the main part in finding and implementing solutions. They must do this in collaboration with other persons while fully using and integrating their expertise in civil engineering and abilities they have acquired from what they have seen and experienced. The Construction Management Committee of JSCE proposes the disaster-response management capabilities as stated below. It is believed that developing and implementing education programs focusing on enhancing expertise and abilities backed by experience will help foster disaster-response management capabilities.

"Disaster response management capabilities" =

"Expertise about disasters" $\times$ "Abilities backed by experience" 


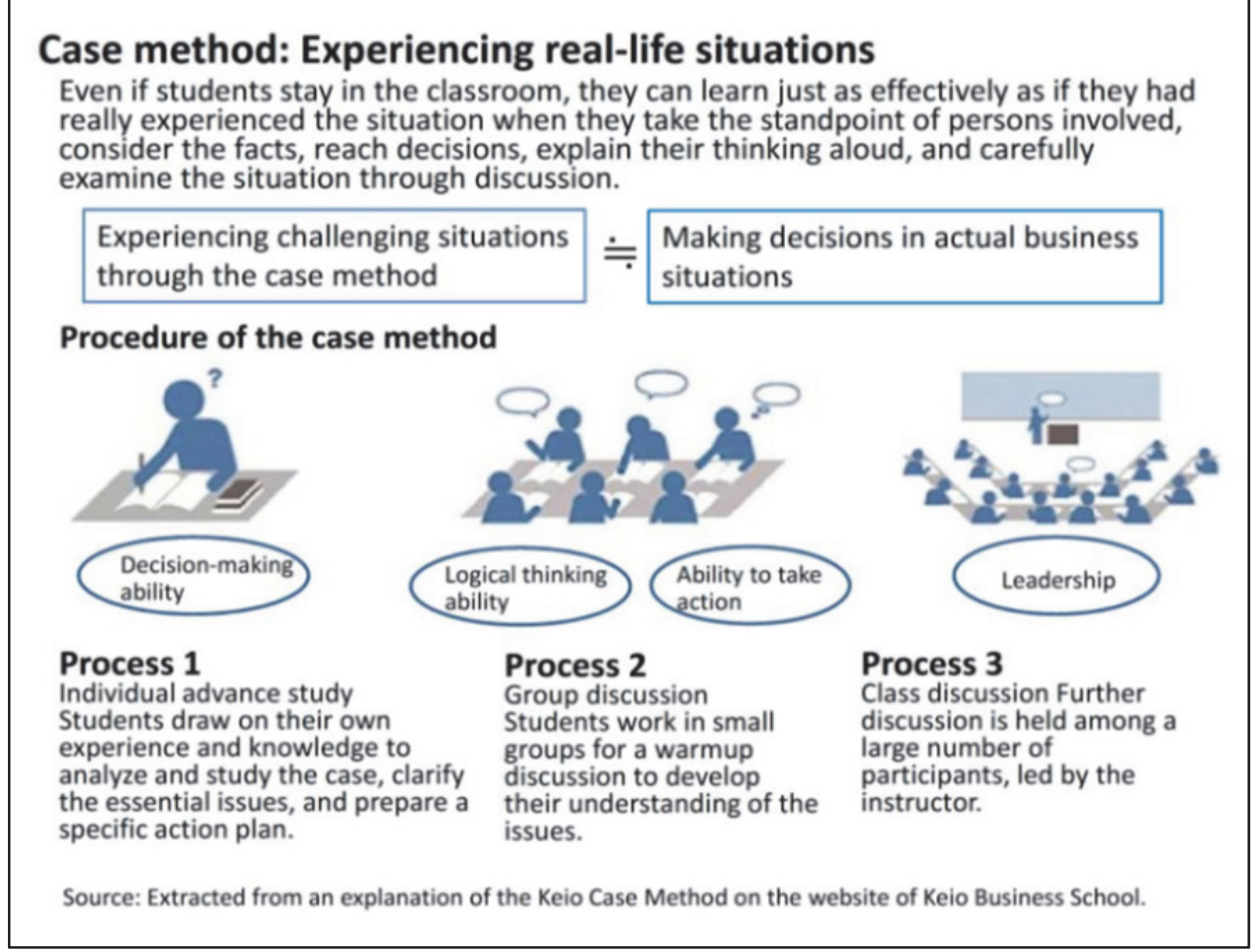

Fig. 2 Case method: Experiencing real-life situations Material from the website of Graduate School of Business Administration, Keio University, with some revisions.

The following [1] through [9] are the "abilities backed by experience" that have been specified based on the three cases discussed in classes, namely, "the initial response taken by the Tohoku Regional Development Bureau," "the initial response taken by Soma City" and "restoration of the Sendai Airport Terminal Building."

[1] Capability to collect and analyze pieces of information

[2] Capability to systemize the analyzed information to solve challenges

[3] Capability to create multiple solutions through logical thinking by fully utilizing and integrating information and knowledge from a comprehensive view

[4] Capability to make decisions on solutions to problems faced from an objective view while taking ethical and limited conditions into account

[5] Capability to explain ideas to a team and obtain its approval

[6] Capability to explain ideas to team members and obtain their approval

[7] Capability to control oneself to achieve challenges and continue to work together for achievement

[8] Capability to adjust thoughts and actions in response to circumstances without being caught up in practices and rules

[9] Capability to judge where the responsibility lies and make decisions based on one's own thoughts and actions.
In this context, "expertise" about disasters is expert knowledge in engineering (civil engineering, structural engineering, disaster-prevention engineering, etc.) that individuals have, which are necessary for overcoming disaster response-related challenges.

\section{USE OF THE CASE METHOD IN DISASTER RESPONSES}

\section{(1) Previous study of case method}

The case method was developed as a practical approach for management education about 80 years ago under the initiative of Harvard Business School. In Japan, it has been adopted by Keio Business School and other institutions and upgraded ${ }^{3)}$.

Classes using the Case Method at business schools aim to "create new ideas with teamwork through discussions" on actual business cases. There's a problem encountered when highlighting text. Please revise "in a simulation through the identified cases" to:through simulation using identified cases. A feature of this approach is that it gets trainees to think and judge things from the standpoint of a character in the case and deepens their understanding through group discussions. It can be said that the key point lies in developing the ability to judge by yourself, rather than finding and learning correct answers ${ }^{2)}$. Figure 2 shows the learning process using the case method. 
In Japan, from the middle of the 2000s, the case method has been increasingly introduced in a wide range of educational fields with practical situations as well as management education, aimed at not only fostering researchers but also educating students and developing practitioners.

Sugimoto et al. ${ }^{4)}$ have carried out courses of education that allow trainees to intensively experience a lot of situations in a simulation by using very short cases, consisting only of tens of lines, which are considerably shorter compared to cases used in general case methods. For those who cannot gain enough experience from actual projects alone, such short cases serve as an in-house education tool for making up for their lack of experience.

Fujisaki and Ozawa ${ }^{5)}$ are engaged in creating prototypes of the case method in the construction field based on complaints related to construction work during the night-time. Target trainees are engineers with a certain level of experience in construction project management. Effects on practical education of management techniques using video have been confirmed.

Sano ${ }^{6)}$ recognizes the effectiveness of the case method, saying that the biggest advantage in adopting the case method to develop human resources at professional graduate schools, etc. is that in order to cultivate their decision-making ability, trainees are able to experience a lot of situations in a simulation for a short time that they can otherwise only rarely experience. Sano also points out the importance of measuring the learning effects on trainees and accumulating research results in order to enhance the learning effects of the case method.

As part of practical efforts for active leaning in university education, Yonemitsu et al. ${ }^{7)}$ have established the Learning Management System (LMS) and e-Learning "online class" and created its content, video-based learning materials on the theme of "disaster prevention" education. It has been noted that trainees were able to obtain a deep understanding about the subject through active discussion during the class using these learning materials.

As is evident from these previous studies, the case method is being adopted in a variety of education fields. For now, however, there are very few cases that touch upon the approach aimed at developing practitioners capable of crisis management in the event of a large-scale disaster.

This paper reports on case studies as well as efforts to make practical use of the case method in developing disaster-response management capability.

\section{(2) Application of the case method in disaster responses}

The case method is a possible approach to develop

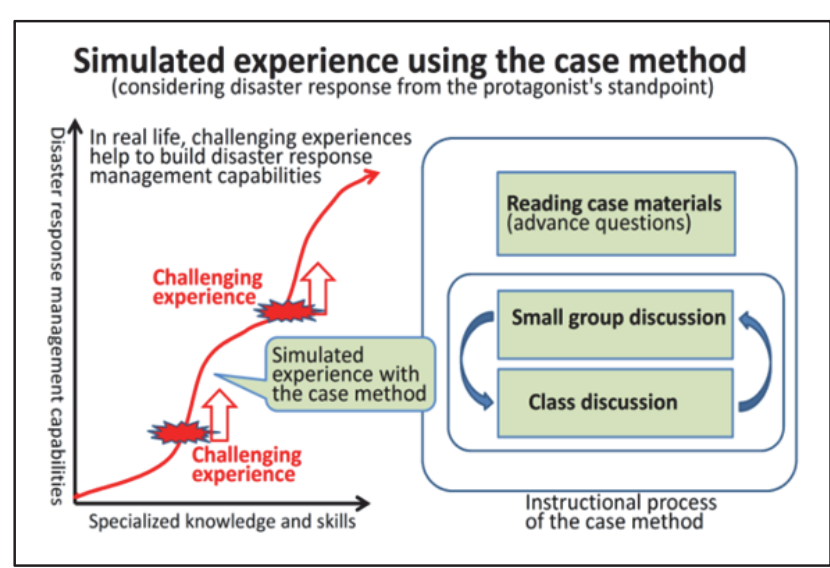

Fig. 3 Simulated experience using the case method.

response capabilities in practical situations in the field of construction. From the following viewpoints, this approach is considered to be more effective for fostering disaster-response management capabilities. (i) Management in the event of a disaster requires responses that go beyond basic rules and manuals under emergencies.

Disaster response (initial response) requires flexibility to respond to emergencies. Judgments and actions taken by entities and individuals in such a situation cannot be in line with basic rules and manuals. Some situations may require responses that go beyond manuals and other situations may require extralegal responses. It can be expected that not only learning basic rules and manuals but also studying examples of responses actually taken under tough situations will produce significant effects.

(ii) Responses are taken with collaboration and cooperation between various entities and individuals

Disaster responses are taken with collaboration and cooperation between various entities and individuals, but they are not carried out as previously agreed because the respective entities and individuals make judgments, and take actions in a flexible manner in emergencies as stated above. Learning what results were finally obtained from individuals' judgments and actions through actual cases is expected to be very effective for learning what efforts are required to establish mutual trust on a daily basis, in addition to making arrangements such as cooperation agreement, effective joint training, and exercises,.

In the business administration field, it is possible to transmit expertise and skills through textbooks and manuals. However, it is difficult to disseminate collective capabilities and insights to be exercised based on such expertise and skills in writing. It is difficult to cultivate such abilities without practical experience of challenging situations. The same applies to the field of disaster response. The abilities of responsible persons to make judgments and decisions 
to tackle challenges at the time of a disaster (collective capabilities, insights, etc.) are the disaster-response management capabilities.

Figure 3 shows the concept of simulated experience through the case method learning examined in this study.

As illustrated in this figure, the case method is an approach that enables trainees to experience challenging situations in a simulation. As it is extremely valuable to get practical experience in challenging situations today, it can be said that experiencing such challenging situations in a simulation is also very useful. In particular, in consideration of the rarity of a disaster and the unique features of disaster-response management (flexibility, etc.), the usefulness of the case method in the field of disaster response is expected to be extremely high.

\section{DEVELOPMENT OF 11 CASES BASED ON ACTUAL EXAMPLES OF THE GREAT EAST JAPAN EARTHQUAKE}

\section{(1) A framework of case development}

This study takes up the "disaster-response management in the Great East Japan Earthquake" as the main theme. Thus, with the aim of increasing disaster-response management capabilities, it is necessary to develop cases that can serve as learning materials to be used in the case method classes. In general, a case should not be just a report or list of facts and events; to make it better, the case should be developed with the following taken into account:

- Education themes meet the goals.

- The content is easy-to-understand for the trainees and arouses their interest.

- It poses a question to the trainees and they are easily aware of it.

- The trainees are able to analyze and examine the content on their own.

- The trainees are able to completely role-play as decision makers.

- The content requires discussion.

Based on the above generalities, the following five principles were defined for case development in this study.

[1] Who is the main player? It is clear from whose standpoint trainees should make judgments.

[2] All the information necessary (enough) for making judgments is provided.

[3] Knowledge (legal system, structures,techniques, etc.) the trainees should obtain prior to receiving the training is indicated in advance.

[4] The time sequence of events is indicated in an easy-to-understand manner in order to prevent misunderstanding of their development. (Display the date and time of occurrence as accurately as possible.)

[5] Context is provided in an easy-to-understand manner using 5W1H (who, what, when, where, why, and how) in order to avoid any misunderstanding by the trainees.

\section{(2) Eleven cases developed in this study}

The cases to be used in the class using the case method are not intended to present successful examples of disaster response, but to give the trainees an opportunity to think about disaster-response management by themselves.

This study calls critical situations "challenging situations." The main player responsible for disaster-response management will experience various situations; in particular, things that make him/her irresolute, things that force him/her into a dilemma, and scenes in which he/she has to deal with events that are not stated in manuals or rules under "challenging situations." These are important points that give the trainees an opportunity to think from the main player's standpoint. The trainees are not always required to give answers to these cases because the aim is to give them food for thought. Table $\mathbf{1}$ is a list of the 11 cases developed in this study and their challenging situations. Figure 4 illustrates a specific case (No. 2).

The trainees learn actual situations of disaster response through classroom training. In order to enable them to undergo a simulated experience, it is extremely important for the case developers to describe a challenging situation skillfully.

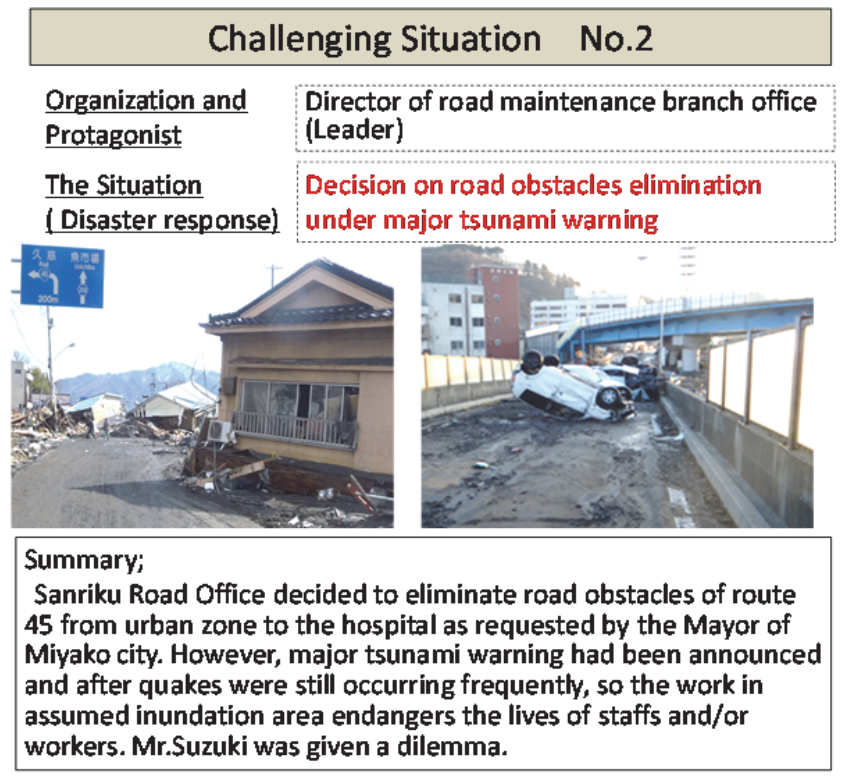

Fig. 4 Challenging Situation of decision on Case No. 2. 
Table 1 Eleven cases developed in this study.

\begin{tabular}{|c|l|}
\hline NO. & \multicolumn{1}{|c|}{ Title } \\
\hline 1 & $\begin{array}{l}\text { Emergency support for a wide range of materials and equipment to affected municipalities: } \\
\text { Flexible response by the disaster response headquarters of the Regional Development Bureau }\end{array}$ \\
\hline 2 & $\begin{array}{l}\text { Road closure and road obstacle clearing under tsunami warning: } \\
\text { Decisions and actions of the head of the Regional Development Bureau branch office }\end{array}$ \\
\hline 3 & $\begin{array}{l}\text { Emergency restoration of key roads: } \\
\text { Mito Management Office of the East Nippon Expressway Company }\end{array}$ \\
\hline 4 & $\begin{array}{l}\text { Securing wide-area transportation routes: } \\
\text { Shipping route obstacle clearing in harbors }\end{array}$ \\
\hline 5 & $\begin{array}{l}\text { Searching for missing persons under difficult conditions: } \\
\text { Decisions by the Soma municipal construction manager }\end{array}$ \\
\hline 6 & $\begin{array}{l}\text { Initial response of local government's crisis management department: } \\
\text { Kamaishi city, Iwate Prefecture }\end{array}$ \\
\hline 7 & $\begin{array}{l}\text { Ensuring safety of evacuees in airport buildings: } \\
\text { Actions by the president of the Sendai Airport Terminal Building }\end{array}$ \\
\hline 8 & $\begin{array}{l}\text { Procurement of disaster relief supplies by the Japan Federation of Construction Contractors : } \\
\text { Facing comprehensive procurement needs }\end{array}$ \\
\hline 9 & $\begin{array}{l}\text { Voluntary road obstacle clearing by local businesses, etc.: } \\
\text { Cooperative initial response by a community's public and private sectors }\end{array}$ \\
\hline 10 & $\begin{array}{l}\text { Local construction industry association involvement: } \\
\text { Activities of the Sendai Construction Industry Association }\end{array}$ \\
\hline 11 & $\begin{array}{l}\text { Disaster response by local construction companies: } \\
\text { Initial response of Hashimototen Co. after the earthquake }\end{array}$ \\
\hline
\end{tabular}

To this end, the descriptions which the developers have written for the cases listed in Table 1 cover the following seven elements: (i) Property of the main player: the workplace at which he/she works and what he/she is responsible for; (ii) Details of the disaster response: how he/she responded to the disaster; (iii) Details of the challenging situation: what troubled him/her, what he/she had to manage, etc.; (iv) Disaster response management capability to be enhanced through learning the case; (v) Knowledge that should be acquired; (vi) Points in discussion; and (vii) Class/learning approaches, etc.

These elements are included in the case text and reference materials to be distributed to trainees and teaching notebooks for instructors separately.

Visual information such as charts and pictures is incorporated in the case text. There are sufficient margins on each page so that it is not filled with writing. One case text has up to 15 to 20 pages. The text does not provide all information - rather, it is important to reduce the information to the minimum necessary for the main theme.

\section{(3) Clarification of goals and target participants of the case method training}

It is important to clarify the training goals and who should be the target trainees prior to conducting the case method training. Under the guidance of experts, the goals and target trainees are specified as follows:

\section{a) Goals of learning}

[1] Preparation that has been found to be effective (or not effective) at the time of a disaster

Learn how preparing for a disaster (development of manuals, execution of emergency drills, agree- ments with relevant entities, etc.) was utilized or not. In addition, learn how the experience of a disaster and disaster response in the past were utilized.

[2] Response that goes beyond basic rules and manuals in emergencies

Disaster response (initial response) requires flexibility to respond to emergencies. Judgments and actions taken by entities and individuals in such a situation cannot always be in line with rules and manuals. Some situations may require responses that go beyond them and other situations may require extralegal responses. Therefore, learn examples of responses actually taken under tough situations as well as basic rules and manuals.

[3] Response through collaboration and cooperation of entities and individuals during an information communication blackout

Disaster responses are taken with collaboration and cooperation between various entities and individuals, but they are not always carried out as previously agreed partly because of the breakdown of information communication networks or "responses with flexibility" by respective entities/individuals as stated above. The trainees must learn what results are finally obtained from individuals' judgments and actions. In addition, they will learn the importance of concluding a prior agreement of cooperation, execution of joint drilling, and establishment of mutual trust.

\section{b) Target trainees}

These include persons who are engaged in daily operations in the construction field and also responsible for management in a specific field under the direction of top management. They also include 
those who may be required to exercise disaster-response management capabilities under a disaster response system in the event of a disaster. (As a precondition, they should have knowledge of basic matters relating to social infrastructure development.)

\section{IMPLEMENTATION OF SIMULATION CLASSES USING THE CASE METHOD}

Since FY2014, the Construction Case Method Promotion Subcommittee of JSCE has carried out simulation classes using the 11 developed cases to determine whether or not the case method is effective for developing disaster-response management capabilities. In FY2015 the case method was introduced in administrator training courses for beginners at the College of Land, Infrastructure, Transport and Tourism as well as the Tohoku Regional Development Bureau of the Ministry of Land, Infrastructure, Transport and Tourism (MLIT). It is regarded as an effective approach for developing management capabilities. This section describes how to conduct a class using the case method and gives an outline of the simulation class held in FY2014.

\section{(1) How to conduct a class using the case method}

Whether the case method works well or not largely depends on the attitude and willingness of participants and abilities of instructors. Therefore, simulation classes encourage participants to take active responses. In this context, teaching styles used in external seminars were referred to and the adoption to actual training programs was taken into account when the style of simulation classes was designed.

As its style, a simulation class is 3.0 hours long with 20 to 30 trainees. It consists of four parts starting with the introduction part:

- Orientation (to reach common understanding about the case)

- Group discussion (four to five members per group)

- Class-wide discussion

- Conclusion.

Points to note for proceeding with the class efficiently are stated below.

a) Preparation for class and preliminary questions

Basically, the trainees are required to prepare for class. The class begins with trainees asking questions to have a shared understanding for smooth discussion; they will not be given an explanation about the case in the class. An effective approach is to give them a preliminary question sheet together with the case text for preparation in order to have them give answers to the sheet and submit it prior to the class. With this approach, instructors will be able to know trainees' ideas and skills prior to the class, which can lead to smooth discussion.

\section{b) Group discussion}

The main part of the class is a class-wide discussion. To have the class run smoothly, it is effective to have group discussion among trainees only before the class-wide discussion. The aim of the group discussion is not to integrate opinions as a group. It is thought that listening to others' opinions through small-group discussion contributes to enhancing each trainee's opinion, which in turn makes the subsequent class-wide discussion better.

\section{c) Role playing}

In some cases there may be persons with totally different ideas. It is effective if they, as players from respective standpoints, debate different ideas on how to respond to the challenging situation. This approach is also beneficial to trainees who are not players because they can organize their thoughts through listening to the debate among players.

\section{d) Class-wide discussion}

The class-wide discussion is held in the final phase of the class. Based on the education theme for each case, instructors need to proceed with the discussion in such a way that the trainees can reach some awareness about disaster-response management.

The main roles of the instructors in the class-wide discussion should include asking questions to the trainees, encouraging them to express their ideas and get involved in the discussion actively, encouraging trainees to write their answers on the board, and asking them deeper questions. Thus, the instructors must be fully capable of smoothly and comprehensively handling class matters.

Do's and don'ts for the instructors in the class-wide discussion are as follows: guide the trainees in such a way that they can reach some awareness by themselves; encourage them to speak out; do not force opinions on the trainees; and do not deny what the trainees state.

\section{(2) Implementation of simulation classes}

Simulation classes using the developed cases were carried out in many places, with the aim of reviewing how to conduct classes, fostering, instructors, and enhancing the quality of cases (learning materials) as well as promoting the use of case method in the development of the disaster-response management capabilities. Members of the Construction Case Method Promotion Subcommittee of JSCE served as instructors.

In the United Nations World Conference on Disaster Risk Reduction held in March 2015, the following four simulation classes were reported. 
a) Simulation class in Osaka (August 22, 2014)

Case used: Case No. 2 "Road Closure and Road Obstacle Elimination under Major Tsunami Warning"; no. of trainees: Approximately 20 participants from industry, academia, and government in the construction field

In the class, a disaster video was screened as a way of giving the trainees a sense of realism. In addition, role-playing exercises, in which trainees were asked to act as branch manager, main player, and site representative from a construction company in charge of road obstacles, were carried out to encourage the trainees to experience the challenging situation in a simulation.

b) Class as part of training programs at College of Land, Infrastructure, Transport and Tourism (November 19, 2014)

Two lessons of the large-scale earthquake and tsunami measures program of a specialized course for FY2014.

Carried out as a class. Case (No. 2) used; no. of trainees: 27

Adequate feedback was given by trainees; they pointed out that even if the main player of the themed case had made the right decision and choice, we should not turn it into a grand story.

c) Two lessons of the environmental and urban engineering program at Nagoya Institute of Technology (for third-grade students) (November 19, 2014)

Case used: Case No. 7 "Security of Evacuees in Isolated Airport Building"

No. of trainees: Approximately 50 students of the above program

It has been found that it is important for the trainees who attend the case method class to have prior knowledge of the theme.

d) Simulation class in Sendai (Approximately three hours on December 3, 2014)

Carried out backed by Tohoku Regional Development Association

Case used: Case No. 7 "Security of Evacuees in Isolated Airport Building”

No. of trainees: Approximately 20 participants including those from industry, academia, and government in the construction field, medical care-related parties and administrators of facilities such as department stores or accommodations

It has been verified through this simulation class that the case method is also effective in developing disaster-response management capabilities of the public.

The cases used in the aforementioned classes (No. 2 and No. 7) are shown Fig. 5.

Figures 6 and 7 show scenes from a group dis- cussion and a class-wide discussion in Sendai, respectively. Figure 8 shows the results of a survey that was conducted after the simulation class in Osaka. The questionnaire asked the trainees "Is the case method a suitable and effective means of developing disaster-response management capabilities?”

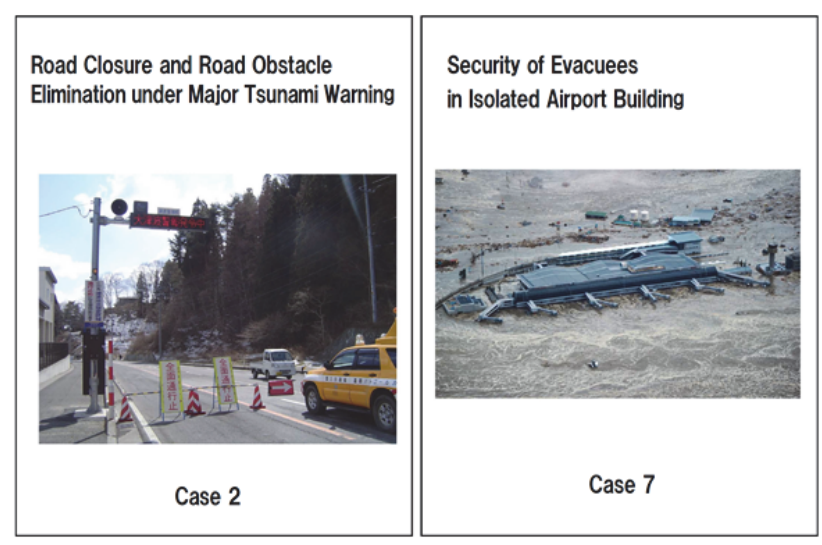

Fig. 5 Cases No. 2 and No. 7.
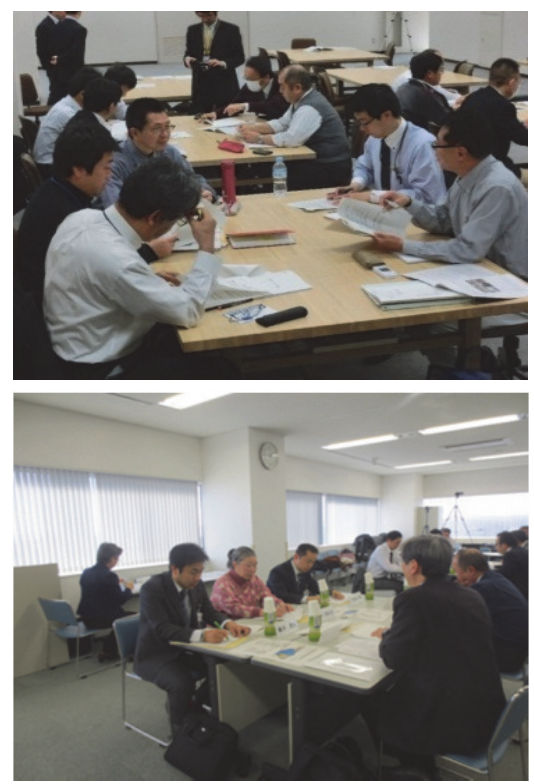

Fig. 6 Group discussion (Upper: College of Land, Infrastructure, Transport and Tourism; Under: The class in Sendai).

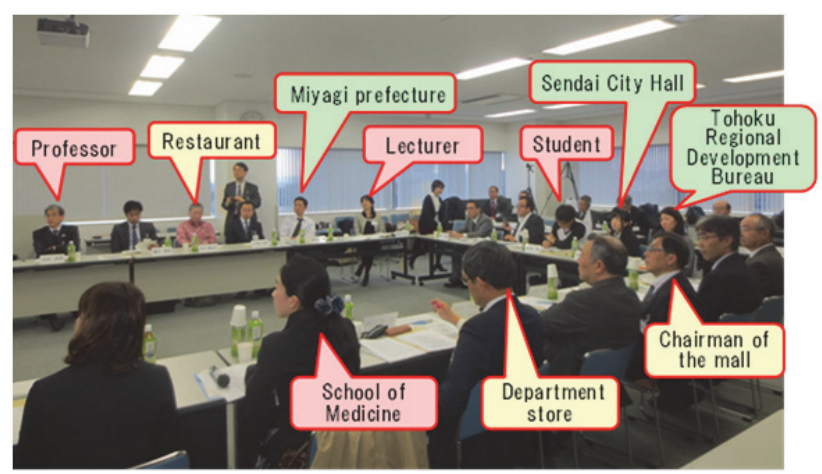

Fig. 7 Class-wide discussion (class in Sendai). 


\section{Is the case method a suitable and effective means of developing disaster response management capabilities?}

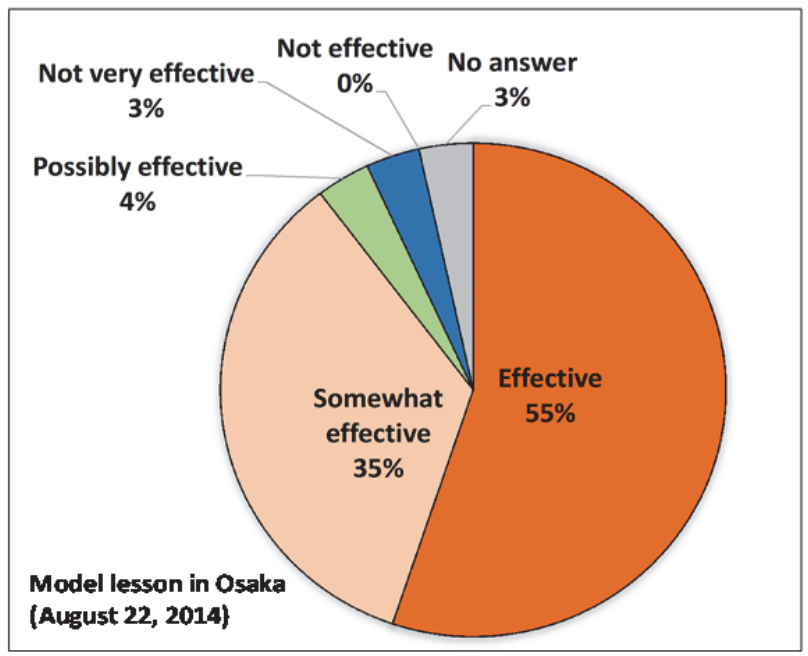

Fig. 8 The result of questionnaire investigation on Model lesson in Osaka.

The results of questionnaire surveys targeted at the trainees of (i) to (iv) show that the case method was well received as stated below:

- I was able to experience (somewhat) reality: $80 \%$

- (More or less) some awareness came to me: over $80 \%$

- Effective in developing disaster-response management capabilities (to some extent): $90 \%$ to $100 \%$

\section{ACTIVITIES TO PROMOTE THE CASE METHOD}

During the two years between 2015 and 2016, training programs using the developed cases were carried out at the College of Land, Infrastructure, Transport and Tourism (four classes of disaster prevention training courses) and the Tohoku Regional Development Bureau of the (MLIT) (eight classes of administrator training courses). The case method is currently being introduced on a full-scale basis.

In FY2016, technical training courses were carried out for different levels of managers. This section analyzes the effects of using the case method in disaster-response management based on the results of questionnaire surveys targeted at the managers.

\section{(1) Outline of in-service training courses using the case method}

This paragraph describes an outline of two training courses using the case method; one is targeted at middle management (Technical Managers or equivalent at offices of the MLIT) and the other is targeted at entry-level management (new Assistant Managers or equivalent at offices of the MLIT).

a) College of Land, Infrastructure, Transport and Tourism (June 15, 2016)

- Comprehensive course for construction management for FY2016

- Case used (No. 1)

- No. of trainees: 17 (Technical managers at offices of the MLIT)

The case used explains the flexible response taken by the disaster response headquarters of the Regional Development Bureau in emergency support for a wide range of materials and equipment to affected municipalities. This training course is the first course that used case No. 1. In FY2016, the College of Land, Infrastructure, Transport and Tourism will have three classes in this course.

b) Tohoku Regional Development Bureau (May 18 and August 24 of 2016)

- New Assistant Manager training courses (I) and (II) for FY2016

- Case used (No. 7); no. of trainees 11 (May), 21 (August)

Tohoku Regional Development Bureau is active in using the case method. In FY2016, they held five classes using the case method. Case No. 7 was used in three classes (case No. 2 for the remaining two classes).

(2) Confirmation of the effectiveness of the case method through questionnaire surveys

This section outlines the trainees' straightforward views on the classes using the case method - what was useful and what was confusing - based on the results of questionnaire surveys that were conducted after the training courses.

\section{a) New assistant manager}

[Useful points]

- Listening to others' opinions from different viewpoints was very helpful.

- If I encounter an unimaginable challenging situation in future, I would like to make an appropriate choice by utilizing this simulated experience.

- It would be helpful for me as a leader in making quick decisions on critical management matters.

- I recognized the importance of exploiting image training in daily operations and management.

- It was very helpful in imagining what I would think of and how I would respond if I actually got involved in a challenging situation.

- I learned anticipation and debating capabilities through the case method class.

[Confusing points]

- Various opinions came from the participants in the class-wide discussion, but I was not able to understand fully what was important. 
- The class taught me a lot of things, but it was difficult to imagine an actual state of disaster with this theme.

\section{b) Middle management}

\section{[Useful points]}

- As we have to race against time and make quick decisions in the event of a disaster, a simulation exercise with a sense of urgency in the classroom is important.

- As there may be occasions for us to respond to general people at disaster sites, we need to be ready to respond to unimaginable requests.

- It is important to experience a situation where manuals do not work, including predicted extensive disasters in simulation.

- Harsh choices and decisions based on the views of risk management were of great interest.

- I thought that the use of the case method would enable the development of plans close to practices such as timeline or BCP.

\section{[Confusing points]}

- As the exercise did not indicate a correct answer, I am not sure whether I understood it properly or not.

- As individuals have different opinions and ideas and no correct answers are indicated, we have no choice but to make the best decision on an ad hoc basis.

As indicated above, some respondents had some kind of frustration about not being able to obtain correct answers, which is a feature of the case method, while positive feedback was obtained on the training courses using the case method from both New Assistant Managers and Middle management.

As flexibility is required in responding to ever-changing situations in times of disaster, it is considered that simulation using the case method is an effective way of training regardless of the level of management.

For your reference, the results of responses to the questionnaires on effects of the case method are graphed in Figs. 9 to 11 by question: (i) Did you have

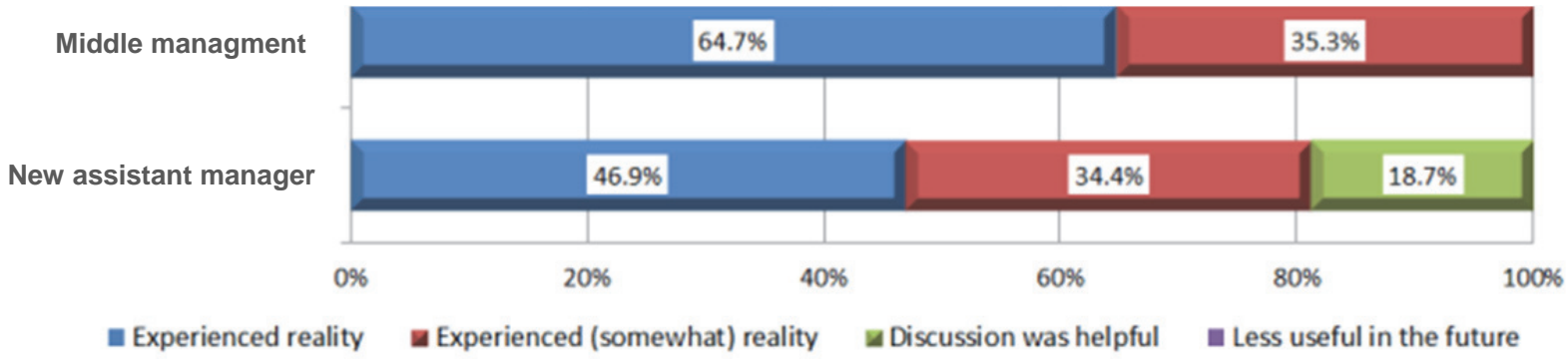

Fig. 9 Did you have a simulated experience through the case method class?.

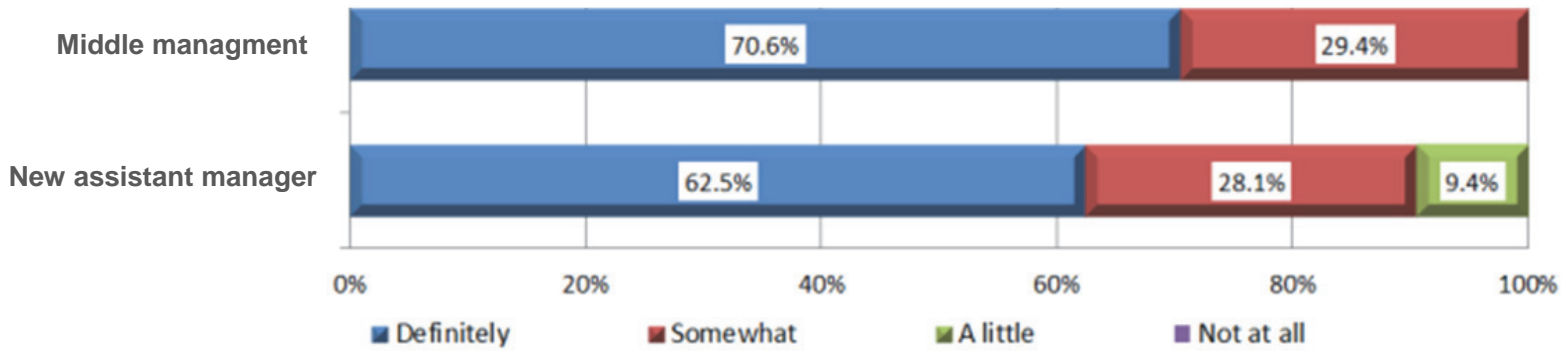

Fig. 10 Did some "awareness" come to you?.

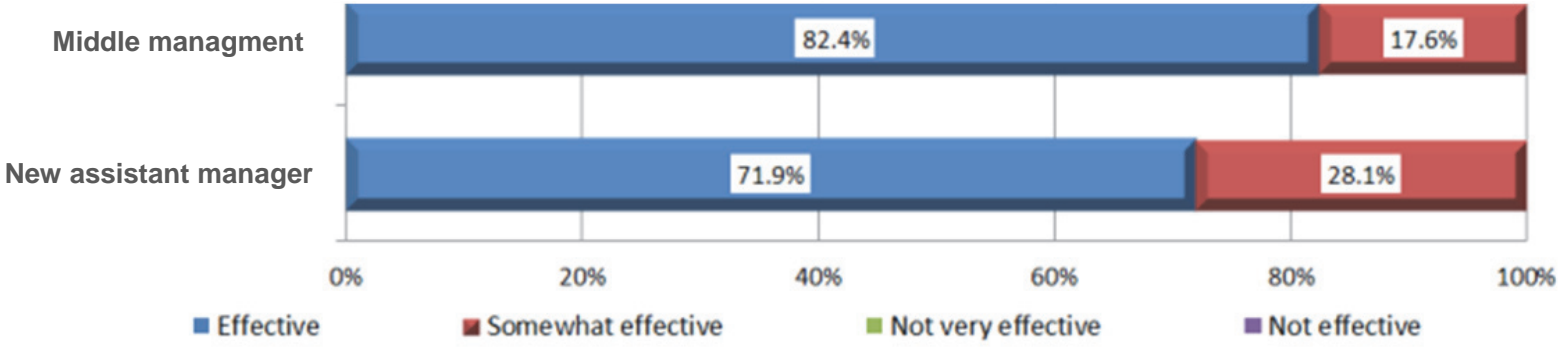

Fig. 11 Do you think the case method is effective in developing disaster response capabilities?. 
a simulated experience through the case method class? (ii) Did some awareness come to you? and (iii) Do you think the case method is effective in developing disaster response capabilities?

Figures 9 to 11 indicate that the training programs using the case method were well received by the middle management. This result shows that compared to new assistant managers, members of middle management who have obtained "ability backed by experience" to appropriately such as disaster response, have a higher regard for in-service training courses using the case method as an effective approach.

\section{CONCLUSION}

In this study, we developed 11 cases based on actual examples from the Great East Japan Earthquake and carried out simulation classes using the cases in order to examine whether the case method is an effective approach to develop disaster-response management capabilities. Results of the examination showed us that experiencing a thinking process in simulation is a very effective way to acquire disaster-response management capabilities and the case method is effective in developing public-level disaster-response management capabilities. The applicability of the case method was observed.

Furthermore, an in-service training course using the case method was carried out, through which the effectiveness was confirmed. The case method is considered useful in developing human resources as well as enhancing abilities to respond to predicted large-scale disasters.

Key points and issues in the application of the case method are as summarized below:

- In running a class, how the instructor leads his/her class and elicits opinions from trainees are important.

- Instructors should play an important role not in drawing a conclusion but in bringing them into discussion so that some awareness comes to them.

- In order to make the class successful, trainees are required to prepare for class and some contrivances are necessary to boost their motivation to partici- pate in the class.

- Because the case method is an exercise without correct answers, it is difficult for the participants to understand.

The case method is considered to be applicable to the development of human resources and entire management in the field of construction. There are high expectations that it will be applied to the construction field.

ACKNOWLEDGMENT: This paper was developed by the authors based on some of the results of the research conducted by the Disaster Response Management Capability Development Workshop and the Construction Case Method Promotion Subcommittee of the Construction Management Committee of JSCE. The authors are deeply grateful for the workshop and to all related parties for their assistance during this study.

\section{REFERENCES}

1) Japan Society of Civil Engineers: Report by the Disaster Response Special Task Committee of the Great East Japan Earthquake Followup Committee, 2012.

2) Japan Society of Civil Engineers: Research report on the development of disaster-response management capabilities in the construction field, a priority theme for research for FY2013, 2013.

3) Website of Keio Business School, Graduate School of Business Administration, Keio University;

http://www.kbs.keio.ac.jp/about/casemethod.html (accessed 2016.10.1).

4) Sugimoto, Y., Suzuki, K. and Okusawa, K.: The merits of using short cases for the case method practice for a project manager, Proceedings of The Society of the Project Management Fall 2011 Research Presentation Conference, pp.126-130, 2011.

5) Fujisaki, Y. and Ozawa, K.: Practice and effect of case method using audio-visual case, Journal of Construction Management, Vol.13, pp. 255-262, 2006.

6) Sano, T.: Principle to improve the effect of case method learning, Rcus Working Paper of Research Center for University Studies, University of Tsukuba, No.4, pp.1-22, 2013.

7) Yonemitsu, K., Kawamichi, T., Koga, T., Kuge, J., Toshiro, M., Fukuzaki, Y. and Hoyashita, S.: A practical study of the active learning utilizing LMS, Journal of Saga University Organization for General Education, Vol.4, pp.175-188, 2016.

(Received November 9, 2016) 